\title{
AN INTERNET-BASED COMMUNICATION MODEL FOR A/E/C INDUSTRY
}

\author{
Manar Shami ${ }^{1}$, Ph.D., and Hazem Elzarka ${ }^{2}$, Ph.D. \\ ${ }^{1}$ Assist. Prof. Construction Science Dept., Univ. of Cincinnati, 2220 Victory Parkway, \\ Cincinnati,OH45206,email: manar.shami@uc.edu \\ ${ }^{2}$ Assist. Prof. Construction Science Dept., Univ. of Cincinnati, 2220 Victory Parkway, \\ Cincinnati, OH45206, email: elzarkhm@email.uc.edu
}

\begin{abstract}
Among the most significant factors contributing to projects' success in the $\mathrm{A} / \mathrm{E} / \mathrm{C}$ industry is effective communication. One shortcoming of current project websites is that the published information may be static and does not enable professionals to take advantage of the wide range of functionality available through the Internet. This has generally led to an overflow of information that may not be useful to all project participants. This paper proposes a new model called the "smart document" that enables higher level of communication and collaborations among all parties. Other developments have helped create a common platform that significantly enhances the performance of processes such as bidding and procurement.
\end{abstract}

Keywords: Smart Document, Communication Channel, Project Website, Collaboration

\section{INTRODUCTION}

Construction management is an informationintensive industry in which communication plays a vital role. Communication involves the transfer and sharing of information among owners, contractors, designers, suppliers, subcontractors and other project participants. Effective communication has been considered as one of the most significant factors contributing to the success of a construction project. In an investigation by the Property Services Agency in the UK, nearly two thirds of the problems in the construction industry such as cost overrun, time delay, compromise to quality, and contractual disputes; were found to be caused by inadequate communication. It was thus no surprise that a survey of architectural firms conducted by Bentley Systems, Inc. indicated that $94 \%$ of respondents were making project collaboration their primary automation goal for the new millennium [1].

Recognizing the importance of communication, many companies and organizations have explored the use of local area networks (LAN) and wide area network (WAN) to link all project participants. A number of Architecture/Engineering/Construction (A/E/C) companies have built extensive networks that linked their offices and construction sites to facilitate communication, reinforce client support, and provide a good understanding about the status of their projects with respect to cost, schedule, quality, and safety. More recently, with the rapid growth of the Internet, more companies are exploring the potential of developing project specific websites for facilitating interaction among all parties. This paper starts by comparing the conventional communication model used in construction with a proposed internetbased communication model.

The advantages of project specific websites and their shortcomings are then discussed. The paper then presents a new model, the "smart document" that has the potential of diminishing many of the shortcoming associated with static and less efficient project specific websites that are currently in use.

\section{CONVENTIONAL COMMUNICATION MODEL}

Any effort to improve the communication process in the construction industry should start with developing a model of the conventional process that is currently in use. Figure 1 depicts such a model. This Figure illustrates the conventional model, in which each organization directly communicates with one or more other organizations. Many factors influence the level of direct communication. These 
factors include the size of the project and the project delivery system (i.e. general contracting, construction management, design/build, etc.) used.

The direct communication model results in a large number of communication channels and sacrifices the quality and efficiency of the communication process. For example, a typical event that needs to be communicated to several parties in a construction project is a change order. Assuming a contractor needs to issue a change order as a result of different site conditions. The contractor will have to communicate the change order to the owner, designer and all suppliers and subcontractors affected by the change. According to the conventional communication model, the contractor will most likely communicate the change order for a number of times, depending on the number of parties involved. As the number of parties increases, the process becomes very inefficient. If the change order is not communicated in certain manner to all the affected parties, misunderstanding and perhaps confusion might occur leading to potential claims and cost or schedule overruns.

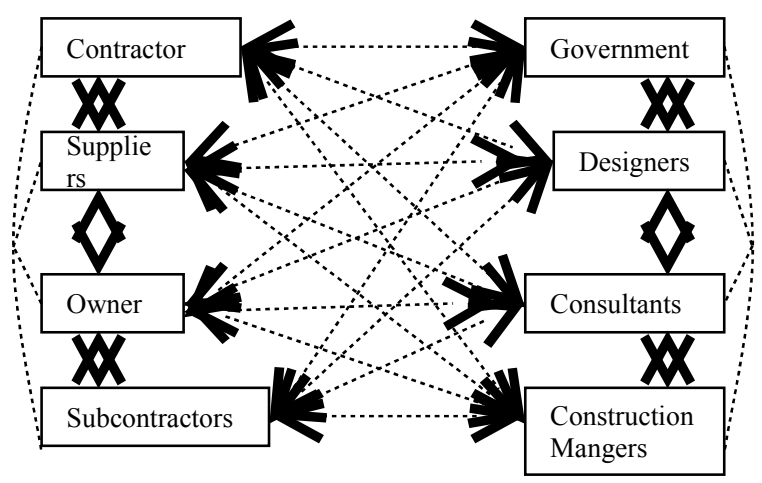

Communication
Channel

Figure 1. Conventional Communication Model

\section{INTERNET-BASED COMMUNICATION MODEL}

As illustrated in Figure 2, in an internet-based communication model, all parties communicate through an Internet server. In the change order example discussed above, the contractor can communicate the content of the change order by publishing it on the server. All parties affected by the change order will have access to the server and can review the proposed changes on-line. The Internet server does not only reduce the number of communication channels but also improves the quality of communication by standardizing the content of the messages [5].
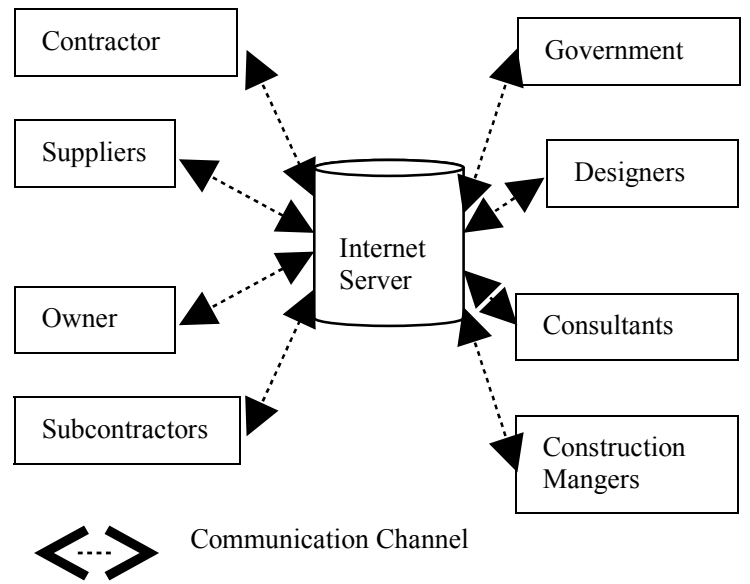

Figure 2. Internet-based Communication Model

Figure 3 illustrates a comparison between the conventional communication model and the internetbased communication model. As depicted in Figure 3 , the internet-based model is much more efficient especially as the number of parties or project participants increases.

\begin{tabular}{|l|c|c|}
\hline $\begin{array}{c}\text { \# of } \\
\text { parties }\end{array}$ & $\begin{array}{c}\text { \# of channels in } \\
\text { conventional } \\
\text { comm. model }\end{array}$ & $\begin{array}{c}\text { \# of channels in } \\
\text { Internet-based comm. } \\
\text { Model }\end{array}$ \\
\hline 2 & 1 & \\
\hline 3 & 2 & \\
\hline 10 & 4950 &
\end{tabular}

Legend: $\bigcirc$ Server $\bigcirc$ Party (sender)

Figure 3. Conventional vs. Internet-based Communication Model 


\section{PROJECT SPECIFIC WEBSITES}

Realizing the potential benefits of an internetbased communication model as discussed above, many companies have implemented project specific websites. These websites enable contractors to place sensitive construction project information on the World Wide Web in a password-protected environment thereby limiting the number of people having access. A project website enables project teams to leverage the Internet to find, present, discuss, review, and track project-related information in real-time. Various types of information; e.g., CAD files, database queries, procurement documents, and others can be virtually published, and dynamically maintained on a project website

There are various options that a company can select from when implementing a project specific website [2]. These options can be categorized as follow:

- Service bureau products: such as e-Builder from MPInteractve (http://www.mpinteractive.com/), ProjectCenter from Evolve (http://projectcenter.evolv.com/), Advantage PCS from Emerging Solutions, Inc. (http://www.emergingsolutis.com/). These products offer owners the option of developing project websites without investing time, energy, or resources into acquiring the necessary skills for web development. The advantage of a service bureau product is that the user only needs Internet access and rudimentary Internet skills to create a full-service project specific websites.

- Internet-based construction software packages: such as ActiveProject from Framework Technologies Corp. (http://ww.frametech.com/), allow the user to set up the project websites on any server. This approach gives the user more control over the appearance of the websites and their security.

- Off-the shelf generic internet publishing software: such as Lotus Notes, and FrontPage. These applications require a much smaller initial capital investment, but demand greater maintenance efforts. Microsoft FrontPage, for example, allows users to create useful and attractive websites without requiring knowledge of programming languages such as JavaScript, or HTML. This option is only appropriate for a user who has a capable and available in-house computing staff.
Project specific websites can be based on the Internet communication model discussed above and have many of their advantages, namely increased efficiency and consistency of communication. In their present form, however, project specific websites have a large disadvantage, which is information overflow. A lot of information that is posted to them, may not be relevant to all users of these websites. If the content placed on a website is not directly relevant to a project team, the team will not use the site for accessing information [3]. A more "intelligent" communication approach called the "smart document," has been developed to solve the information overflow problem as well as various other in-efficiencies as will be described in the next section.

\section{THE "SMART DOCUMENT" MODEL}

In this model [6], each transaction, for example an issuance of RFI (Request For Information), is referred to as a "smart document" (SD). A SD is defined as a container of useful project information. As shown in Figure 4, the SD consists of six components; control unit, classification code, dependency recorder, usage recorder, version recorder, and route map recorder. Each of these components performs a specific task to facilitate the role of the SD in the project.

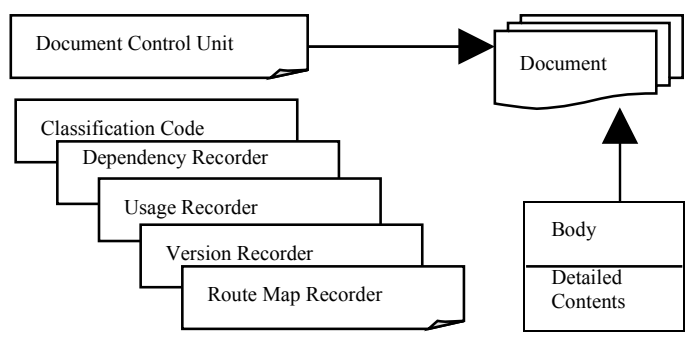

Figure 4. The Anatomy of a Smart Document (SD)

The classification code is the identification number of the SD. This code is unique and indicates to which organizations, processes, or sub-processes the document belongs. The dependency recorder stores information on the relationship between the document and other documents and describes the extent to which the document is overlapped with others in terms of purpose, contents, and life cycle. The usage recorder stores information on the users of the document and on what actions need to be taken in light of the contents of the document. The version recorder stores information on the documents' 
updating and retrieval history. The route map recorder stores information on the routes of the document and contains all feasible scenarios that would describe the possible routes and their associated duration and destinations.

A smart document may contain several multimedia objects such as text, images, audio, video, etc. Under the proposed "smart document model", communication is achieved by intelligently transmitting and sharing dynamic SDs over the Internet instead of using paper-based documents as in the case of the conventional communication model or static electronic document as in the case of project specific websites.

As illustrated in Figure 5, the life cycle of a SD consists of different phases: planning, generation, transmission, sharing, file recording and in some cases, re-use of the document in other projects. During the life cycle of a document, supportive (or sub) documents may be needed or generated to complete the life cycle of the original document at hand. These supportive documents have their own life cycles, which are generally shorter than that of the original one. Examples of supportive documents, include, phone calls, inquiries, letters, requests for quotation, transmittals, etc.

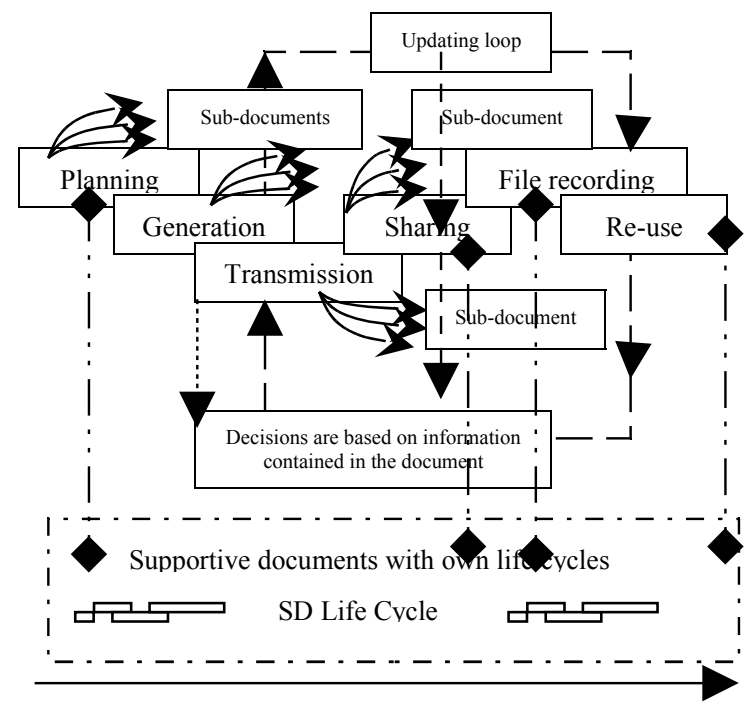

Figure 5. Life Cycle of a Smart Document (SD)

The life cycle of a project, on the other hand, is viewed as a combination of the life cycle of all generated documents. As illustrated in Figure 6, the project life cycle will consist of the sums of hundreds or perhaps thousands of SDs (that have their own life cycles) that were generated to complete the project as seen in Figure 6.

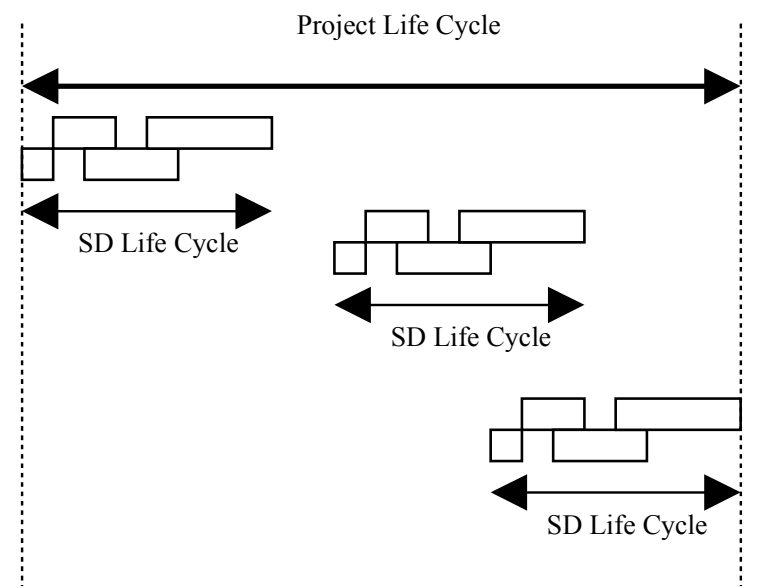

Figure 6. Project Life Cycle

The smart document described above is considered "intelligent" because it can determine its destination. As illustrated in Figure 7., the destination can be an individual, organization, process, subprocess, or the central database. The SD could be sent to multiple destinations simultaneously. An "organization" in this research refers to any of the parties involved in the project (e.g. owner, contractor, architect, government, supplier, etc.)[4]. A "process" refers to the functional department or team that is working on a task or tasks. Each process is broken down into a number of sub-processes that can be part of one or more organizations. For example, the design process at an engineering firm can be broken down into sub-processes such as conceptual design, detailed design, rendering, etc.

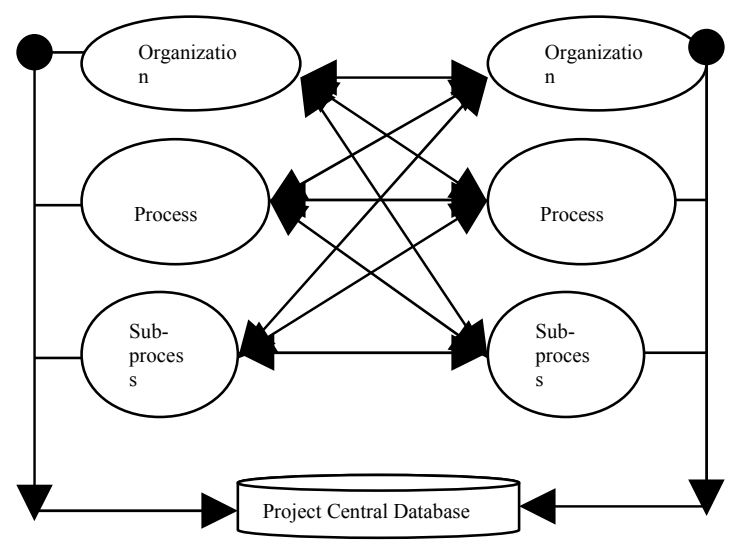

Figure 7. Example of SD Routes

The central database is an Internet-based distributed document database in which documents 
may be physically stored at different locations. The database includes all SDs that are generated, used, and stored during the entire project life cycle.

Figure 8 illustrates how documents are used throughout all phases of a project and then stored in a central database hub for easy retrieval and re-use. This database will become the impetus for a future intelligent knowledge base that will help in controlling the entire phases and flow of SDs.

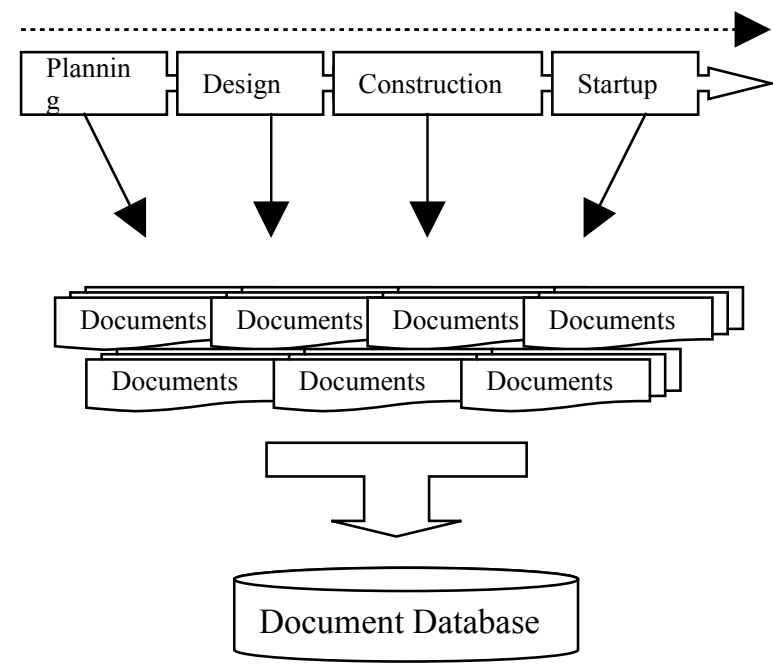

Figure 8. Distributed SD Database

The flow of documents between communication objects (e.g. organization, process, sub-process, database) is controlled by a "Smart Communication Check Port" (SCCP). The SCCP can identify the information contained in the SD and based on this information, it suggests the optimal document route map; just like "Routers" in computer networks. The SCCP can also identify related documents stored in the database and link them to the SD to facilitate decision-making.

The following example illustrates the role of the SCCP. While sending an SD (in the form of an email) to a supplier to request a price quotation, an individual picks up the wrong person in the mailing list. When the email SD reaches the SCCP, the SCCP would check the information stored in the SD. After identifying the error, the SCCP would send the SD back to the sender requesting correction and/or clarification and suggesting alternative recipients. Several other examples can be mentioned in other processes such as billing, scheduling, and design.

\section{CASE STUDY: MODELING THE} "BIDDING PROCESS"
The bidding process in the construction industry is chosen as being one of the important processes that involve a high degree of communication and interaction among various organizations and processes. Typically, owners and contractors are the main organization involved in this process, however, other organizations get involved in bidding, such as designers, subcontractors, and suppliers. Processes that interact with bidding may include estimating, procurement, and design as shown in Figure 9 below.

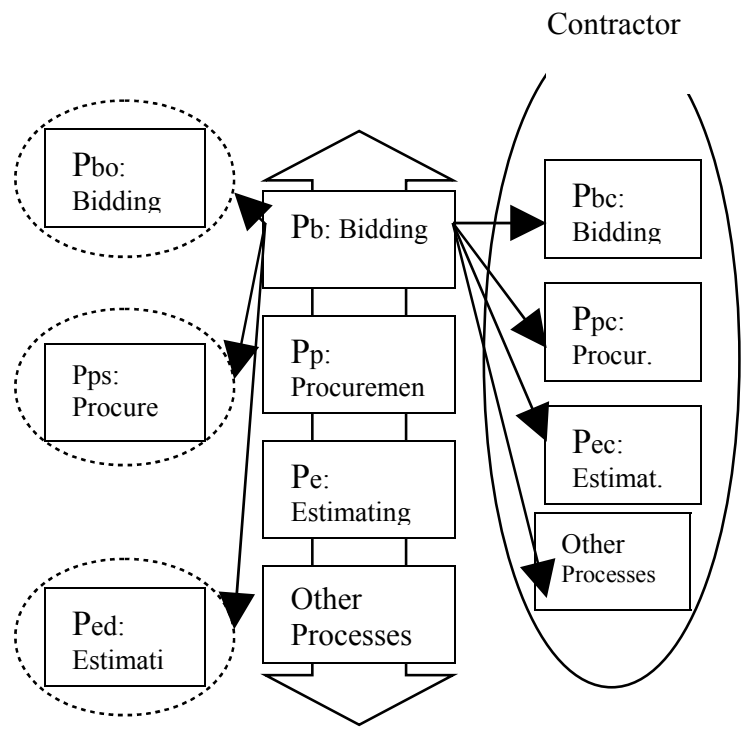

\section{Legend:}

\author{
$\mathrm{Pb}:$ Bidding Process \\ $\mathrm{Pe}$ : Estimating Process \\ Pp : Procurement Process \\ Pbo : Bidding Process within owner's organization \\ $\mathrm{Pbc}$ : Bidding Process within contractor's \\ organization \\ Pps : Procurement Process within supplier's \\ organization \\ Ped : Estimating Process within the designer's \\ organization
}

Figure 9. Bidding Process Conceptual Design

The above model is used to create a detailed bidding process that can be found in [6]. This model leads to identifying all related (SDs) as transactions in the bidding process for a construction project, and from the perspective of a contractor's organization. The number of SDs that can be generated in this process can be large enough to discourage any efforts 
aimed at tracking down each SD for further investigation and optimization. The proposed system described above allows for more flexibility in classifying SDs and defining the specific objectives of every SDs in contributing to project goals.

\section{CAD DOCUMENT AS AN ILLUSTRATION OF A "SD"}

To illustrate the "smart document" concept, a CAD drawing will be considered. A CAD document is typically issued as a typical bid document by the designer to the contractor, and is generated using a CAD-based software system. In the "smart document" model, this document is assigned a unique classification number so that it can be tracked to a specific organization and process. Upon the generation and approval of the CAD document, it is issued as part of the bidding package that will be used by various potential contractors to bid the project. An estimating team analyzes the CAD document and prepares an estimate after other "supportive documents" may be issued such as request of information and request for quotation from potential suppliers. Assuming there was an error in the CAD document; the owner may ask the designer to modify the CAD document and then submit it to the contractors for re-estimating. The SCCP will identify all contractors that the CAD document needs to be submitted to. After bid evaluation and award, the CAD document becomes part of the contract documents, which are all stored in the central database.

In the above scenario, all communication occurs over the Internet with minimal human interaction and interference. The CAD smart document knows where and when it should go because of the intelligence contained in it.

\section{CONCLUSIONS}

The internet provides an ideal platform for electronic communication. Using the Internet, construction project management teams can share and transfer information electronically at a very low cost, compared with other communication means. A shortcoming of the Internet as a communication tool is the information overflow. Such an overflow may underline the usefulness of the internet. The paper presented a "smart document" model to help solve the shortcoming discussed above. The model ensures that any document is generated at the right time, contains the correct information and only transmitted to the relevant parties.

\section{Acknowledgement}

The author wishes to express his gratitude to the School of Civil and Structural Engineering at Nanyang Technological University (NTU), Singapore, for its initial support of this research. Also, the author would like to thank Mr. Zhong Bailing, a former graduate student at NTU, for his tireless efforts and assistance in obtaining information and working on several parts of this research.

\section{REFERENCES}

[1] Phair, M. (1998). "Collaborative Systems Move Closer." ENR, 241(2), 42.

[2] Capano, C.D., D. C. Stahl amd M. McGeen, "Educating Future Constructors Utilizing a Project Specific Website, Proc. Construction Congress VI, ASCE, Orlando, Florida, February 2000, pp. 234-244

[3] Babcock K and M. O. Federle " Project Specific Websites to Improve Communication on Job Sites", Proc. Construction Congress VI, ASCE, Orlando, Florida , February 2000, pp. 174-183

[4] Schermerhorn, J.R., Hunt, J.G., and Osborn, R.N., "Managing Organizational Behavior," John Wiley \& Sons, Inc., New York, NY, 1994

[5] Bjork, B-C, "Computers in Construction; Research,, Development and Standardization Work in the Nordic Countries," Working Group for Information Technology, Nordic Building Research. 1985; and Bjork, B-C, "the Integrated Use of Computers in Construction-the Finish Experience," Program Report, Nordic Building Research (NBS). 1987

[6]Zhong, Bailing, “An Intelligent Internet based Decision Support System Model for Total Synergy and Integration of Construction Project Management Processes and Organizations, FYR, Nanyang Technological University, Singapore. 1999. 